\title{
Evaluation of sub-acute changes in cardiac function after cisplatin-based combination chemotherapy for testicular cancer
}

\author{
R Altena', EC de Haas', J Nuver', CAJ Brouwer', MP van den Berg ${ }^{3}$, AJ Smit', A Postma ${ }^{2}$, DTh Sleijfer \\ and JA Gietema*,I
}

'Department of Medical Oncology, University Medical Center Groningen and University of Groningen, P.O. Box 30.00I, Groningen 9700 RB,

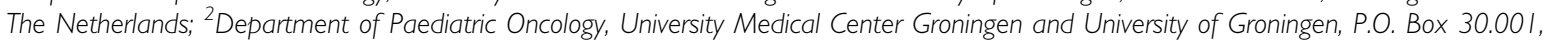
Groningen 9700 RB, The Netherlands; ${ }^{3}$ Department of Cardiology, University Medical Center Groningen and University of Groningen, P.O. Box 30.00 I, Groningen 9700 RB, The Netherlands; ${ }^{4}$ Department of Internal Medicine, University Medical Center Groningen and University of Groningen, P.O. Box 30.00I, Groningen 9700 RB, The Netherlands

Long-term cardiovascular morbidity is increasingly observed in chemotherapy-treated testicular cancer survivors, but little is known of early sub-clinical changes in cardiac function. We prospectively evaluated cardiac function in testicular cancer patients by echocardiography. Systolic (Wall Motion Score Index) and diastolic (E/A-ratio and Tissue Velocity Imaging (TVI)) parameters, and serum levels of N-Terminal pro-Brain Natriuretic Peptide (NT-proBNP) were assessed before the start of chemotherapy and I year later. Echocardiography data were compared with an age-matched group of healthy controls. Forty-two patients treated with bleomycin, etoposide and cisplatin were evaluated (median age 27 years, range 18-50). Systolic function and E/A-ratio did not change, whereas the median TVI decreased ( 12.0 vs $\left.10.0 \mathrm{~cm} \mathrm{~s}^{-1} ; P=0.002\right)$. Median levels of NT-proBNP increased (5 vs $18 \mathrm{pmoll}^{-1}, P=0.034$ ). Compared with controls, TVI before the start of chemotherapy was not significantly different. In conclusion, we found that at a median of 10 months after cisplatin-based treatment for testicular cancer, TVI decreased significantly, indicating a deterioration of diastolic cardiac function. Serum levels of NT-proBNP increased. The prognostic significance of these changes for future cardiovascular morbidity is not clear.

British Journal of Cancer (2009) I 00, I86I-1866. doi: I0.1038/sj.bjc.6605095 www.bjcancer.com

Published online 19 May 2009

(c) 2009 Cancer Research UK

Keywords: testicular cancer; cardiovascular toxicity; echocardiography; prospective

Testicular cancer (TC), the most frequent type of solid malignancy in young male adults, has become a highly curable disease since the late 1970s with the introduction of cisplatin-containing chemotherapy regimens. In the growing population of TC survivors, the occurrence of long-term treatment-induced organ damage is increasingly recognised as an important cause of morbidity (Feldman et al, 2008). Compared with the general population, long-term TC survivors have a higher incidence of second malignant neoplasms and cardiovascular disease (Meinardi et al, 2000; Strumberg et al, 2002; Huddart et al, 2003; van den Belt-Dusebout et al, 2007).

In earlier studies, investigating cardiac morbidity in long-term TC survivors at a median of 7-14 years after chemotherapy, we found diastolic dysfunction in $17-33 \%$ of patients (Meinardi et al, 2000; Nuver et al, 2005a). Sub-clinical signs of vascular toxicity were found in a prospective study in TC patients 10 weeks after cisplatin-based chemotherapy (Nuver et al, 2005b). Still, little is known about (sub-) acute cardiotoxicity in TC patients, and to our knowledge, no studies report on early cardiotoxicity. Furthermore, it is not established which parameters are useful in the early assessment of cardiac damage.

*Correspondence: Dr JA Gietema; E-mail: j.a.gietema@int.umcg.nl Revised 26 March 2009; accepted 22 April 2009; published online 19 May 2009
In addition to obtaining insight in the extent and timing of cardiac complications of chemotherapeutic treatment for TC, evaluation of parameters for early (sub-clinical) cardiac dysfunction may enable the identification of patients who are at risk for future cardiovascular events. Echocardiography is a convenient and frequently used method to assess cardiac function, enabling evaluation of both systolic and diastolic function parameters. Biochemical markers can also be used to evaluate cardiac status. N-Terminal pro-Brain Natriuretic Peptide (NT-proBNP) is produced by ventricular cells in response to increased mechanical load and wall stretch. Plasma levels are used as a prognostic indicator in different stages and causes of cardiac disease (Doust et al, 2005). However, its role in detecting chemotherapy-induced cardiac morbidity has not been established yet (Bryant et al, 2007; Ekstein et al, 2007).

In this prospective cohort study, we investigated echocardiographic and biochemical changes before and at 1 year after the start of cisplatin-containing chemotherapy for disseminated TC.

\section{PATIENTS AND METHODS}

\section{Patients}

All consecutive patients with disseminated TC, scheduled to receive cisplatin-containing chemotherapy as first-line therapy 
at the University Medical Centre Groningen, the Netherlands, between December 2000 and October 2004 were asked to participate in a study investigating the chemotherapy-induced acute cardiovascular toxicity (Nuver et al, 2005b). Exclusion criteria were extra-pulmonary visceral metastases, earlier radiotherapy, pre-treatment history of cardiac disease, use of erythropoietin and an age older than 55 years at the start of chemotherapy. The study was approved by the local ethics committee and written informed consent was obtained from all participants.

After orchidectomy, all patients received three or four threeweekly courses of combination chemotherapy consisting of bleomycin (30 mg on days 2, 8 and 15), etoposide $\left(100 \mathrm{mg} \mathrm{m}^{-2}\right.$ on days $1-5$ of each course) and cisplatin $\left(20 \mathrm{mg} \mathrm{m}^{-2}\right.$ on days $1-5$ of each course). Patients were admitted to the hospital for hydration with 31 of $0.9 \% \mathrm{NaCL}$ per day during the first 6 days of each course. All patients received dexamethason and odansetron as standard anti-emetic therapy.

Reference data were obtained from healthy male siblings of adult childhood cancer survivors, who had participated as control subjects in a cross-sectional study on late cardiovascular sequelae of treatment for childhood cancer. Out of these healthy male siblings, a control group was selected with a comparable median age as the TC patients. Measurements in the controls were carried out under similar circumstances and methods.

\section{Measurements}

Measurements were done within 1 week before the start of chemotherapy and $\sim 1$ year after the completion of treatment.

\section{Echocardiography}

Echocardiography was carried out by a skilled technician at the same laboratory using conventional equipment (General Electrical VIVID 7 system, Horton, Norway, with a $2.5 \mathrm{MHz}$ probe) and consisted of two-dimensional echocardiography, colour-flow mapping and, since 2002, tissue velocity imaging (TVI) (Cheitlin et $a l, 2003$ ). Left ventricular end-diastolic dimension (LVEDD, normal 36-54 mm), left ventricular end-systolic dimension (LVESD, normal 23-40 mm), posterior and septal wall thickness (normal 7-11 mm) were measured on M-mode recordings obtained in the standard left ventricular parasternal long-axis view. The parasternal, transverse and longitudinal dimensions of the left atrium were attained.

For the analysis of systolic function, the left ventricle was divided into 16 segments. Each segment was visually scored between 1 and $4(1=$ normokinesia, $2=$ hypokinesia, $3=$ akinesia, $4=$ dyskinesia). The wall motion score index (WMSI) was the mean score for all the analysed segments. A WMSI of 1.00 was considered normal.

Diastolic function measurements included the mitral valve inflow velocities in early (E) and late (atrial; A) diastole (E/A-ratio, normal >1.00) and tissue velocity imaging of early diastole (TVI Et). Tissue velocity imaging of early diastole was the mean of measurements at the septal, lateral, inferior and anterior mitral annulus (normal $>8.0 \mathrm{~cm} \mathrm{~s}^{-1}$; decreases indicate deterioration of diastolic function). In addition $\mathrm{E} / \mathrm{E}^{\prime}$ was calculated from the peak $\mathrm{E}$ velocity and the mean TVI Et (normal $<15$; increases reflect declines in diastolic function; $\mathrm{E} / \mathrm{E}^{\prime}>15$ is considered as diastolic dysfunction). $\mathrm{E} / \mathrm{E}^{\prime}$ is currently regarded as a sensitive method for assessing diastolic heart failure (Paulus et al, 2007).

\section{NT-proBNP}

$\mathrm{N}$-Terminal pro-Brain Natriuretic Peptide (lower limit of detection $5.0 \mathrm{pmoll}^{-1}$; normal value $<14.75 \mathrm{pmoll}^{-1}$ ) was measured in plasma using an immunoassay (Roche Diagnostics, Mannheim, Germany) from samples that were drawn concomitant with the echocardiographic recordings.

\section{Cardiovascular risk factors (CRFs)}

Cardiovascular risk factors were estimated before the start of chemotherapy. Hypercholesterolaemia was defined as a fasting level of cholesterol $>6.5 \mathrm{mmoll}^{-1}$; diabetes mellitus as a fasting level of glucose $>7.0 \mathrm{mmoll}^{-1}$. Obesity as body mass index (BMI) $>27.8 \mathrm{~kg} \mathrm{~m}^{-2}$. Blood pressure (BP) was estimated as a single recording on one arm in supine position in a quiet room after a minimal rest period of $10 \mathrm{~min}$. Furthermore, an ambulatory $\mathrm{BP}$ device (Spacelab 90207; Spacelabs Inc., Redmond, WA, USA) was used to document BP every $30 \mathrm{~min}$ during a $24 \mathrm{~h}$ period. The control subjects had a single BP recording.

The criteria for hypertension were defined as a mean $24 \mathrm{~h} B P$ $>135 / 85 \mathrm{~mm} \mathrm{Hg}$, a single BP $>145 / 95 \mathrm{~mm} \mathrm{Hg}$ and/or the use of anti-hypertensive medication.

\section{Statistics}

Statistical analyses were carried out in the statistical software package SPSS for Windows version 14.0 (SPSS Inc., Chicago, IL, USA). For comparisons the $\chi^{2}$-test and the non-parametric MannWhitney test were used. To calculate changes within a patient the Wilcoxon signed-rank test was used on the paired samples in those patients where both variables were available. Regressions were calculated with Spearman's correlation. Two-sided $P$-values $\leqslant 0.05$ were considered to indicate significant differences.

Post-hoc power analysis showed that, with a power of $80 \%$ and a two-sided significance level (alpha) of $P<0.05$, a $3.3 \%$ change in TVI Et could be detected in 19 patients, with a correlation coefficient between two measurements under equal circumstances of $\geqslant 0.75$ and variation-coefficient for TVI Et of 7.1\% (Kowalski et al, 2001).

\section{RESULTS}

\section{Patients}

Between December 2000 and October 2004, 65 TC patients were enrolled in the study (Nuver et al, 2005b). In 54 of these 65 patients an echocardiogram was performed before the start of chemotherapy. Twelve out of $54(22 \%)$ patients received no echocardiogram after the completion of cisplatin-based chemotherapy, because of the following reasons: death $(n=1)$, progressive disease $(n=1)$ or logistic reasons (data not evaluable $n=3$; moved out of referral area $n=1$; not performed $n=6$ ). Therefore, 42 patients underwent an echocardiogram before and within 1 year after the completion of cancer treatment. The baseline characteristics like age, disease status and echocardiographic parameters of the patients $(n=12)$ who did not receive an echocardiogram after treatment were not different from the patients that completed two echocardiographic evaluations (data not shown).

Baseline characteristics of the 42 patients with two echocardiographic evaluations are shown in Table 1 . Of the 42 evaluable patients, 12 had pulmonary metastases and one underwent thoracotomy for resection of pulmonary lesions after the completion of chemotherapy.

The control group consisted of 42 healthy males, whose median age was 28 years (Table 2); none of them was known to have co-morbidity.

\section{Echocardiography}

Echocardiography before treatment Before the start of treatment, one out of 33 patients had a WMSI $>1.00(3.0 \%)$. Four out of 41 patients had abnormal wall motion (all local hypokinesia; 
Table I Characteristics of participating patients with testicular cancer

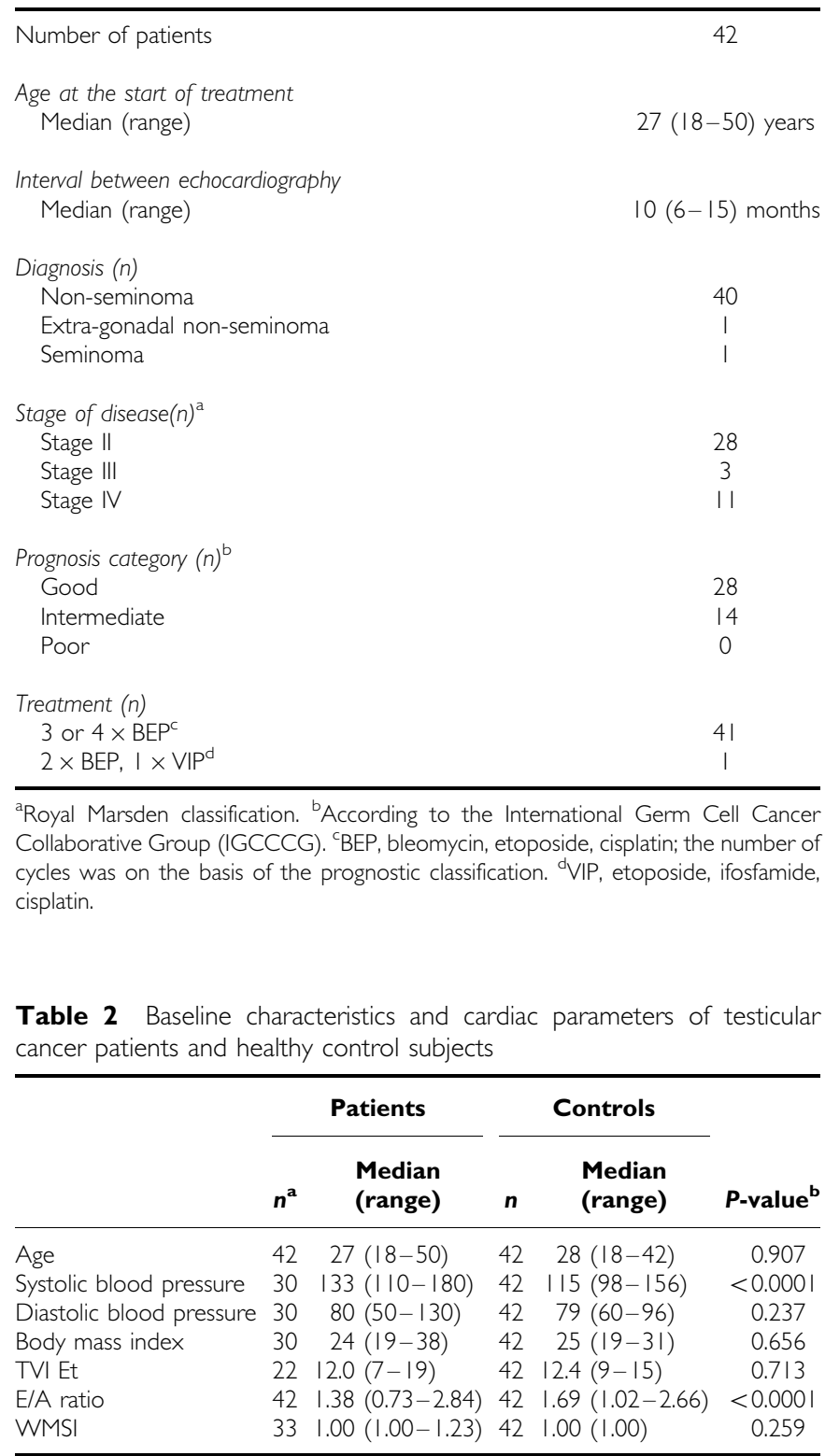

${ }^{a}$ Number of patients in which the respective parameters were available.

bMann-Whitney test.

9.8\%). Three out of 42 had valve dysfunction (pulmonal $(n=2)$ and tricuspid valve insufficiency $(n=1) ; 7.1 \%)$.

The E/A-ratio was $<1.00$ in 8 out of 42 patients $(19.0 \%) ; 1$ out of 22 assessed patients had a TVI Et $<8.0 \mathrm{~cm} \mathrm{~s}^{-1}$ (4.5\%). None of these 22 patients had an $\mathrm{E} / \mathrm{E}^{\prime}>15$. Median values and ranges are summarised in Tables 2 and 3.

Of the controls, 1 out of 42 had had a WMSI $>1.00$. One out of 42 had an E/A radion <1.00; 1 out of 42 had a TVI Et mean $<8.00 \mathrm{~cm} \mathrm{~s}^{-1}$. For median values and ranges, see Table 2 .

The median WMSI and TVI Et in patients and the controls was not different $(P=0.259 ; P=0.713)$, whereas the median E/A-ratio was higher in the controls $(P<0.0001$, Table 2$)$.

Echocardiography after treatment At a median of 10 months after the completion of treatment, 4 out of 28 patients had a WMSI $>1.00(14.3 \%)$. Seven out of 40 patients had wall motion abnormalities (17.5\%, local and/or diffuse hypo- and akinesia).
Table 3 Echocardiographic parameters of testicular cancer patients before and after chemotherapeutic treatment

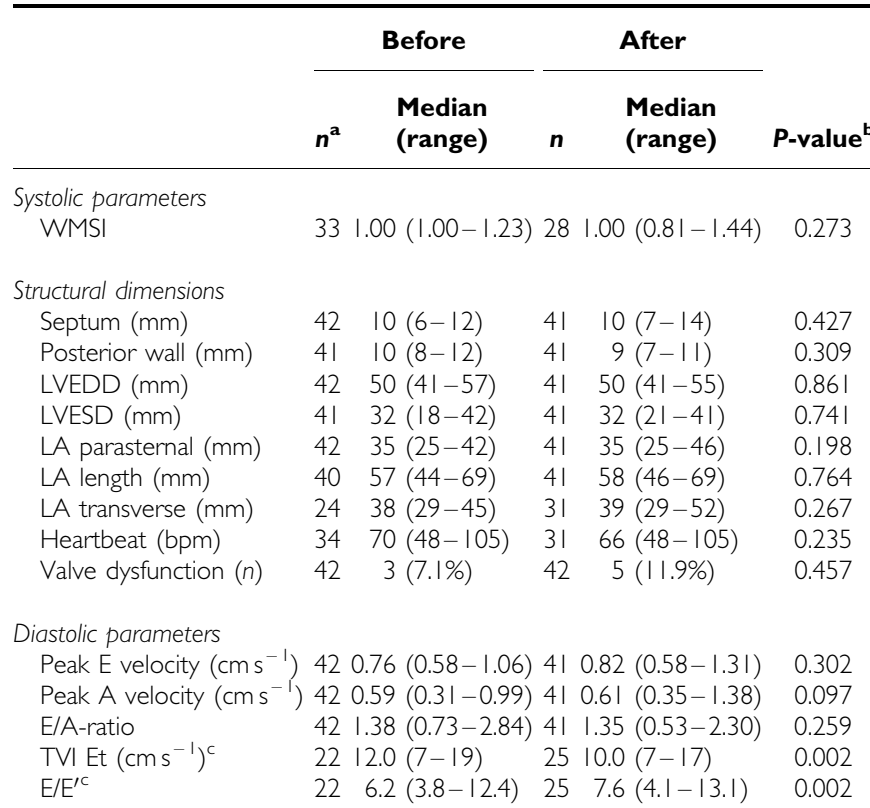

Blood pressure ${ }^{\mathrm{d}}$

$\begin{array}{lllllll}\text { Systolic }(\mathrm{mm} \mathrm{Hg}) & 42 & 129(107-154) & 38 & 123(106-153) & 0.011 \\ \text { Diastolic }(\mathrm{mm} \mathrm{Hg}) & 42 & 74(58-99) & 38 & 70(54-106) & 0.018\end{array}$

${ }^{a}$ Number of patients in which the respective parameters were available. ${ }^{b}$ Wilcoxon signed-rank test. ${ }^{\mathrm{C}} 19$ paired observations available. ${ }^{\mathrm{d}} 24 \mathrm{~h}$ ambulatory blood pressure recordings,

The E/A-ratio was $<1.00$ in 7 out of 41 patients $(17.1 \%) ; 2$ out of 25 assessed patients had a TVI Et $<8 \mathrm{~cm} \mathrm{~s}^{-1}$ (8.0\%). None of the 25 patients had an $\mathrm{E} / \mathrm{E}^{\prime}>15$.

Changes in echocardiography before and after treatment Cardiac dimensions and the median WMSI did not change during the year after treatment (Table 3). The percentage of patients with wall motion abnormalities did not change (9.8 vs $17.5 \%$; $P=0.309$ ), whereas the number of patients with a WMSI $>1.00$ increased $(P=0.01)$. The seven patients with post-treatment wall motion abnormalities included the four patients with pretreatment abnormalities; all of them had deterioration of wall motion abnormalities. Two of them developed pulmonary embolisms during the treatment (Nuver et al, 2005b). Three patients newly developed wall motion abnormalities at 1 year after treatment; one had a myocardial infarction during chemotherapy.

Paired observations of the TVI Et were available in 19 TC patients. The median TVI Et decreased significantly after treatment $(P=0.002$; Figure 1$)$; the median $\mathrm{E} / \mathrm{A}$-ratio did not change (see Table 3$)$. In addition, the median $\mathrm{E} / \mathrm{E}^{\prime}$ increased $(P=0.002$; Table 3).

Age correlated with pre-treatment E/A-ratio $(R=-0.50$; $P=0.001)$, but not with pre-treatment TVI Et $(R=-0.27$; $P=0.219$ ) or $\Delta$ TVI Et (difference between pre- and post-treatment TVI Et; $R=0.21 ; P=0.382$ ).

\section{NT pro-BNP}

The median level of NT-proBNP increased significantly $(n=32$; pretreatment $5 \mathrm{pmoll}^{-1}$ (range $<5-242$ ); post-treatment $18 \mathrm{pmoll}^{-1}$ (range $\left.<5-114\right) ; P=0.034$, Figure 2 ). One extreme 


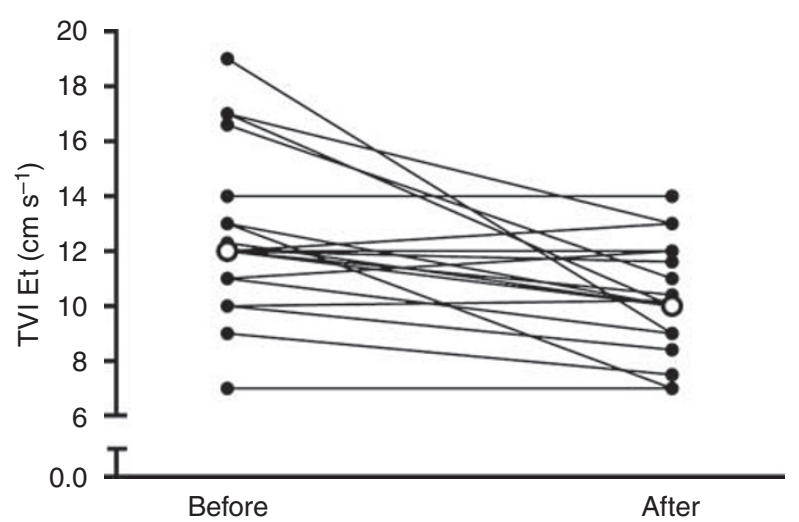

Figure I The tissue velocity imaging of early diastole (TVI Et) in 19 patients before and after chemotherapy; open circles represent median values. Median TVI Et before treatment $12.0 \mathrm{~cm} \mathrm{~s}^{-1}$ (range 7-19), after treatment $10.0 \mathrm{~cm} \mathrm{~s}^{-1}$ (range $\left.7-17\right) ; P=0.002$.

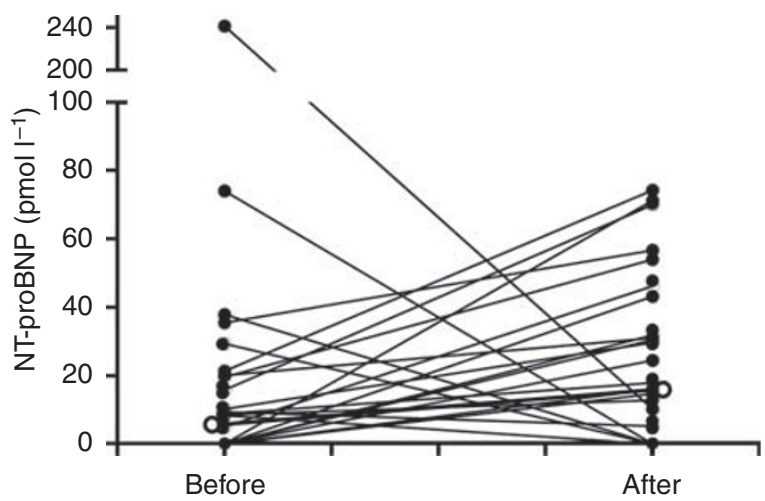

Figure 2 Serum levels of $\mathrm{N}$-Terminal pro-Brain Natriuretic Peptide (NT-proBNP) in 32 patients before and after treatment (normal $\left.\leqslant 14.75 \mathrm{pmoll}^{-1}\right)$; open circles represent median values. Median NTproBNP before treatment 5 pmoll $^{-1}$ (range $<5-242$ ); after treatment 18 pmoll $^{-1}$ (range $\left.<5-|| 4\right) ; P=0.034$.

pre-treatment value $\left(242 \mathrm{pmoll}^{-1}\right)$ was in a patient with a TVI Et of $7.0 \mathrm{~cm} \mathrm{~s}^{-1}$ before treatment.

Levels of NT-proBNP and $\Delta$ NT-proBNP did not correlate with the echocardiographic parameters before and after treatment, and neither correlated with changes in systolic and/or diastolic parameters.

\section{Cardiovascular risk factors}

Before treatment, CRFs of the 42 patients consisted of obesity ( $n=6)$, smoking ( $n=14$ current smokers; $n=5$ former smokers) and hypercholesterolaemia $(n=1)$. The median BMI of the TC patients was $24.2 \mathrm{~kg} \mathrm{~m}^{-2}$ (see Table 2). Nine out of 42 patients (21\%) had hypertension on $24 \mathrm{~h}$ ambulatory BP recordings; 1 out of 42 patients was on anti-hypertensive medication ( $\beta$-blocker). None had diabetes mellitus.

Seven out of 42 control subjects were obese; the median BMI was $25.0 \mathrm{~kg} \mathrm{~m}^{-2}$ (Table 2), which was not different from the TC patients $(P=0.656)$. The systolic BP was significantly higher in the patients $(P<0.0001)$; the diastolic BP was not different $(P=0.237)$.

At 1 year after treatment, CRF consisted of obesity $(n=8)$, smoking (current smokers $n=11$ ) and hypercholesterolaemia $(n=3)$. Four out of 38 patients $(11 \%)$ had hypertension on $24 \mathrm{~h}$ $\mathrm{BP}$ recordings.
Both systolic and diastolic BP decreased after treatment compared with baseline (see Table 3). The pre-treatment systolic BP correlated with $\Delta$ TVI $(R=0.67, P=0.006)$ and the TVI Et at baseline $(R=0.63, P=0.002)$. E/A-ratio and $\Delta \mathrm{E} / \mathrm{A}$-ratio did not correlate with both systolic and diastolic BP. The E/A-ratio in TC patients before treatment correlated with the BMI before treatment $(R=-0.49, P=0.001)$, which was also true for pre-treatment TVI Et and BMI $(R=-0.50 ; P=0.019)$. The WMSI before treatment did not correlate with the BMI.

Smokers had a lower E/A-ratio before treatment (E/A-ratio of smokers 1.31 (range 0.74-2.42) vs non-smokers $1.56(0.87-2.41)$; $P=0.039$ ). The TVI Et as well as other echocardiographic parameters, BP and levels of NT-proBNP were not different between smokers and non-smokers.

\section{Events}

Nuver et al described acute cardiovascular events in this patient group (Nuver et al, 2005b). During treatment, two patients had a myocardial infarction and three had pulmonary embolisms. Omission of patients with cardiovascular events from the analyses did not change the results significantly (data not shown).

\section{DISCUSSION}

In this group of TC patients, we observed changes in TVI Et and $\mathrm{E} / \mathrm{E}^{\prime}$ within 1 year after cisplatin-based chemotherapy, representing a deterioration of diastolic cardiac function. Furthermore, serum levels of NT-proBNP increased.

Several authors report changes in cardiovascular status within years to decades after chemotherapeutic treatment for TC (Meinardi et al, 2000; Strumberg et al, 2002; Huddart et al, 2003; van den Belt-Dusebout et al, 2007), but little is known of the early changes in cardiac function in these patients. Regarding treatmentrelated cardiotoxicity from various cancer treatments, it was recently postulated that diastolic cardiac function deteriorates before the development of systolic dysfunction (Ewer and Lenihan, 2008). In left ventricular dysfunction of various origins, a deterioration of diastolic function can be present in the absence of systolic impairment (Lester et al, 2008), and sub-clinical diastolic dysfunction frequently precedes a drop in systolic parameters (Zile and Brutsaert, 2002).

Echocardiography is a frequently used method for assessing cardiac function, which has the advantage that it enables a reliable estimation of diastolic function by means of more recently introduced parameters, such as TVI Et and E/E'. Other diastolic parameters, like the E/A-ratio, are largely dependent on preload conditions (Hurrell et al, 1997; Sohn et al, 1997), resulting in significant intra-individual variation.

The TVI Et assesses the velocity of the myocardium at different angles from the mitral valve, instead of blood-flow velocities, and is therefore independent of loading conditions (Sohn et al, 1997; Nikitin and Witte, 2004), resulting in less intra-individual variation. This parameter is considered an important and reliable early predictor for the development cardiac dysfunction in other causes of cardiac disease (Nikitin and Witte, 2004). From several small studies in adult childhood cancer survivors, it seemed to be a valuable parameter in defining diastolic (dys-) function (Kapusta et al, 2001; Brouwer et al, 2006; Tassan-Mangina et al, 2006; Galderisi et al, 2007). E/ $\mathrm{E}^{\prime}$ is a derivative of TVI Et and the E velocity, thereby including the end-diastolic left ventricular filling pressure in addition to myocardial velocities. This parameter is currently regarded as a valuable non-invasive method for diagnosing diastolic heart failure (Paulus et al, 2007). Declines in diastolic cardiac function are reflected by increases in $\mathrm{E} / \mathrm{E}^{\prime}$ as well as decreases in TVI Et. 
The pre-treatment echocardiography parameters in our TC patient group corresponded with the same measurements in an age-matched group of healthy controls. In the patient group, a correlation existed between age and pre-treatment E/A-ratio, but not between age and TVI Et or $\Delta$ TVI Et. This is relevant, as ageing is associated with a physiological decline in diastolic cardiac function (Galderisi, 2005). An age-dependent decrease in TVI Et has been shown in healthy controls, but this has only been evaluated in cohorts with larger differences in age and with longer time intervals (Wierzbowska-Drabik et al, 2008).

Several CRFs can lead to declines in diastolic function, including hypertension and obesity (Zile and Brutsaert, 2002). In this study, the pre-treatment systolic BP correlated with $\Delta$ TVI Et. Contrarily, the BMI did not correlate with the changes in TVI Et. The significant decrease in systolic and diastolic BP on the $24 \mathrm{~h}$ ambulatory recordings was also found in the larger study investigating chemotherapy-induced acute cardiovascular toxicity (Nuver et al, 2005b). The causes for this finding are not known, but may at least partly be attributed to a relatively high BP before the start of treatment, which is confirmed by the finding of a higher systolic BP in the patients compared with the age-matched controls. This high BP might be because of stress before the initiation of treatment.

In this study we did not further investigate explanations for this cardiovascular toxicity. The main causes are thought to be related to direct damage to cardiomyocytes and/or the extracellular matrix, as well as sub-clinical vascular injury that induces endothelial dysfunction. Furthermore, the presence of pre-treatment elevations in BP may have resulted in impaired relaxation of the left ventricle, thereby leading to diastolic function decline. Of note, the increase in serum NT-proBNP levels is in accordance with the picture of cardiac damage.

It is unknown whether a deterioration of diastolic cardiac function during the first year after chemotherapy for TC will progress to clinically relevant cardiac disease. It can be hypothesised that the hearts of these relatively young patients can compensate for the chemotherapy-induced damage. On the contrary, they are at increased risk of developing an unfavourable cardiovascular-risk profile (Meinardi et al, 2000; Strumberg et al, 2002; Nuver et al, 2005c; Haugnes et al, 2007), which can contribute to the development of long-term cardiac failure.

In conclusion, we observed significant changes in TVI Et and $\mathrm{E} / \mathrm{E}^{\prime}$ within 1 year after cisplatin-based treatment for TC, indicating a deterioration of diastolic cardiac function. The prognostic significance of this disturbed diastolic function after chemotherapy for future cardiovascular morbidity is not clear, but it might eventually lead to overt cardiac morbidity. Further longitudinal research in TC survivors is needed to obtain more insight in sub-clinical changes in cardiac function.

\section{ACKNOWLEDGEMENTS}

This work was supported by Grant RUG 2000-2177 from the Dutch Cancer Society.

\section{REFERENCES}

Brouwer CA, Gietema JA, van den Berg MP, Bink-Boelkens MT, Elzenga NJ, Haaksma J, Kamps WA, Vonk JM, de Vries EG, Postma A (2006) Long-term cardiac follow-up in survivors of a malignant bone tumour. Ann Oncol 17: 1586-1591

Bryant J, Picot J, Baxter L, Levitt G, Sullivan I, Clegg A (2007) Use of cardiac markers to assess the toxic effects of anthracyclines given to children with cancer: a systematic review. Eur J Cancer 43: 1959-1966

Cheitlin MD, Armstrong WF, Aurigemma GP, Beller GA, Bierman FZ, Davis JL, Douglas PS, Faxon DP, Gillam LD, Kimball TR, Kussmaul WG, Pearlman AS, Philbrick JT, Rakowski H, Thys DM, Antman EM, Smith Jr SC, Alpert JS, Gregoratos G, Anderson JL, Hiratzka LF, Faxon DP, Hunt SA, Fuster V, Jacobs AK, Gibbons RJ, Russell RO (2003) ACC/AHA/ASE 2003 Guideline update for the Clinical Application of Echocardiography: summary article. A report of the American College of Cardiology/American Heart Association Task Force on Practice Guidelines (ACC/AHA/ASE Committee to update the 1997 Guidelines for the Clinical Application of Echocardiography). J Am Soc Echocardiogr 16: $1091-1110$

Doust JA, Pietrzak E, Dobson A, Glasziou P (2005) How well does B-type natriuretic peptide predict death and cardiac events in patients with heart failure: systematic review. BMJ 330: 625

Ekstein S, Nir A, Rein AJ, Perles Z, Bar-Oz B, Salpeter L, Algur N, Weintraub M (2007) N-terminal-proB-type natriuretic peptide as a marker for acute anthracycline cardiotoxicity in children. J Pediatr Hematol Oncol 29: 440-444

Ewer MS, Lenihan DJ (2008) Left ventricular ejection fraction and cardiotoxicity: is our ear really to the ground? J Clin Oncol 26: 1201-1203

Feldman DR, Bosl GJ, Sheinfeld J, Motzer RJ (2008) Medical treatment of advanced testicular cancer. JAMA 299: 672-684

Galderisi M (2005) Diastolic dysfunction and diastolic heart failure: diagnostic, prognostic and therapeutic aspects. Cardiovasc Ultrasound 3: 9

Galderisi M, Marra F, Esposito R, Lomoriello VS, Pardo M, de DO (2007) Cancer therapy and cardiotoxicity: the need of serial Doppler echocardiography. Cardiovasc Ultrasound 5: 4

Haugnes HS, Aass N, Fossa SD, Dahl O, Klepp O, Wist EA, Svartberg J, Wilsgaard T, Bremnes RM (2007) Components of the metabolic syndrome in long-term survivors of testicular cancer. Ann Oncol 18: $241-248$
Huddart RA, Norman A, Shahidi M, Horwich A, Coward D, Nicholls J, Dearnaley DP (2003) Cardiovascular disease as a long-term complication of treatment for testicular cancer. J Clin Oncol 21: 1513-1523

Hurrell DG, Nishimura RA, Ilstrup DM, Appleton CP (1997) Utility of preload alteration in assessment of left ventricular filling pressure by Doppler echocardiography: a simultaneous catheterization and Doppler echocardiographic study. J Am Coll Cardiol 30: 459-467

Kapusta L, Thijssen JM, Groot-Loonen J, van Druten JA, Daniels O (2001) Discriminative ability of conventional echocardiography and tissue Doppler imaging techniques for the detection of subclinical cardiotoxic effects of treatment with anthracyclines. Ultrasound Med Biol 27: $1605-1614$

Kowalski M, Kukulski T, Jamal F, D'hooge J, Weidemann F, Rademakers F, Bijnens B, Hatle L, Sutherland GR (2001) Can natural strain and strain rate quantify regional myocardial deformation? A study in healthy subjects. Ultrasound Med Biol 27: 1087-1097

Lester SJ, Tajik AJ, Nishimura RA, Oh JK, Khandheria BK, Seward JB (2008) Unlocking the mysteries of diastolic function: deciphering the Rosetta Stone 10 years later. J Am Coll Cardiol 51: 679-689

Meinardi MT, Gietema JA, van der Graaf WT, van Veldhuisen DJ, Runne MA, Sluiter WJ, de Vries EG, Willemse PB, Mulder NH, van den Berg MP, Koops HS, Sleijfer DT (2000) Cardiovascular morbidity in long-term survivors of metastatic testicular cancer. J Clin Oncol 18: $1725-1732$

Nikitin NP, Witte KKA (2004) Application of Tissue Doppler Imaging in cardiology. Cardiology 101: 170-184

Nuver J, Smit AJ, Sleijfer DT, van Gessel AI, van Roon AM, van der MJ, van den Berg MP, Hoekstra HJ, Sluiter WJ, Gietema JA (2005a) Left ventricular and cardiac autonomic function in survivors of testicular cancer. Eur J Clin Invest 35: 99-103

Nuver J, Smit AJ, van der MJ, van den Berg MP, van der Graaf WT, Meinardi MT, Sleijfer DT, Hoekstra HJ, van Gessel AI, van Roon AM, Gietema JA (2005b) Acute chemotherapy-induced cardiovascular changes in patients with testicular cancer. J Clin Oncol 23: 9130-9137

Nuver J, Smit AJ, Wolffenbuttel BH, Sluiter WJ, Hoekstra HJ, Sleijfer DT, Gietema JA (2005c) The metabolic syndrome and disturbances in hormone levels in long-term survivors of disseminated testicular cancer. J Clin Oncol 23: 3718-3725 
Paulus WJ, Tschöpe C, Sanderson JE, Rusconi C, Flachskampf FA, Rademakers FE, Marino P, Smiseth OA, De Keulenaer G, Leite-Moreira AF, Borbély A, Edes I, Handoko ML, Heymans S, Pezzali N, Pieske B, Dickstein K, Fraser AG, Brutsaert DL (2007) How to diagnose diastolic heart failure: a consensus statement on the diagnosis of heart failure with normal left ventricular ejection fraction by the Heart Failure and Echocardiography Associations of the European Society of Cardiology. Eur Heart J 28: 2539-2550

Sohn DW, Chai IH, Lee DJ, Kim HC, Kim HS, Oh BH, Lee MM, Park YB, Choi YS, Seo JD, Lee YW (1997) Assessment of mitral annulus velocity by Doppler tissue imaging in the evaluation of left ventricular diastolic function. J Am Coll Cardiol 30: 474-480

Strumberg D, Brugge S, Korn MW, Koeppen S, Ranft J, Scheiber G, Reiners C, Mockel C, Seeber S, Scheulen ME (2002) Evaluation of long-term toxicity in patients after cisplatin-based chemotherapy for non-seminomatous testicular cancer. Ann Oncol 13: 229-236

Tassan-Mangina S, Codorean D, Metivier M, Costa B, Himberlin C, Jouannaud C, Blaise AM, Elaerts J, Nazeyrollas P (2006) Tissue Doppler imaging and conventional echocardiography after anthracycline treatment in adults: early and late alterations of left ventricular function during a prospective study. Eur J Echocardiogr 7: 141 - 146

van den Belt-Dusebout AW, de WR, Gietema JA, Horenblas S, Louwman MW, Ribot JG, Hoekstra HJ, Ouwens GM, Aleman BM, van Leeuwen FE (2007) Treatment-specific risks of second malignancies and cardiovascular disease in 5-year survivors of testicular cancer. J Clin Oncol 25: 4370-4378

Wierzbowska-Drabik K, Krzeminska-Pakula M, Chrzanowski L, Plewka M, Waszyrowski T, Drozdz J, Kurpesa M, Trzos E, Kasprzak JD (2008) Age-dependency of classic and new parameters of diastolic function. Echocardiography 25: 149-155

Zile MR, Brutsaert DL (2002) New concepts in diastolic dysfunction and diastolic heart failure: Part I: diagnosis, prognosis, and measurements of diastolic function. Circulation 105: 1387-1393 